\title{
Retraction Note: Oasis soil composition based on high-resolution image and plant landscape design of park
}

\section{Peng Gong ${ }^{1}$}

Published online: 6 December 2021

C) Saudi Society for Geosciences 2021

Retraction Note: Arabian Journal of Geosciences (2021) 14: 1602 https://doi.org/10.1007/s12517-021-07954-y

The Editor-in-Chief and the Publisher have retracted this article because the content of this article is nonsensical. The peer review process was not carried out in accordance with the Publisher's peer review policy. The author has not responded to correspondence regarding this retraction.

The original article can be found online at https://doi.org/10.1007/ s12517-021-07954-y.

Peng Gong

gp28505587@163.com

1 College of Landscape and Art, Jiangxi Agricultural University, Nanchang 330045, Jiangxi, China 